\title{
EL ANÓNIMO DEL SONETO "NO ME MUEVE, MI DIOS ..."
}

Un estudio reciente ${ }^{\mathrm{I}}$ ha vuelto a llamar la atención sobre el soneto más ilustre de la literatura española, dando nueva actualidad al misterio de su origen. Sister Mary Cyria Huff rehuye prudentemente el atribuir No me mueve mi Dios ... a quienquiera que sea, ateniéndose a la opinión de M. Legendre ${ }^{2}$, de que "tratándose de un país tan profundamente catolicizado como España, no puede menos de dejarnos alguna obra maestra que los historiadores no consigan atribuir a ninguno de los autores conocidos". 'También se conformaba Menéndez y Pelayo con tener el soneto "por obra de algún fraile oscuro, cuyo nombre quizá nos revelen futuras investigaciones" 3 . En cambio, creen otros que el nombre del "fraile oscuro" ha sido revelado desde I9I5 gracias a un hallazgo del benemérito investigador don Alberto $M^{a}$ Carreño: Fr. Miguel de Guevara se llama al agustino mexicano que en $6_{3} 8-0$ tal vez en I634agregó el soneto a su obra manuscrita Arte doctrinal... para aprender la lengua matlaltzinga. Carreño ${ }^{4}$, Alfonso Méndez Planearte ${ }^{5}$ y últimamente Víctor Adib ${ }^{6}$ insisten en atribuir el soneto a este misionero de $\mathrm{Mi}$ choacán, a pesar de que ya en 1626 aparece impreso en Madrid por Antonio de Rojas en un manojo de "poesía mística" que sirve de apéndice a su Vida del espiritu. Y es que el soneto A Cristo crucificado no se en-

1 Sister Mary Cyria Huff, The sonnet "No me mueve, mi Dios". Its theme in Spanish tradition, The Catholic University of America Press, Washington, I948. (Cf. la reseña de Víctor Adis en $N R F H$, III, I949, págs. 90-9I). La autora no utilizó el importante estudio dedicado al soneto por los PP. Scrurfammer y Wicki en el apéndice II de su nueva edición de Epistolae S. Francisci Xaverii aliaque ejus scripta, t. II (vol. 68 de los Monumenta Historica Societatis Jesu), Roma, I945, págs. 526-535.

2 Citado por Hurf, op. cit., pág. $3^{8}$

3 Menéndez y Pelayo, De la poesía mística, Discurso de entrada en la Real Academia Española (1881). (Incluído por el autor en la primera serie de sus Estudios de crítica literaria, $3^{4}$ ed., Madrid, I9I5, págs. 49-50).

4 Alberto M" Carreño, "No me mueve, mi Dios, para quererte". Consideraciones nuevas sobre un viejo tema, México, 1942. (Tomado de la revista Divulgación Histórica).

5 Poetas Novohispanos: Primer siglo (1521-1621). Estudio, selección y notas de Alfonso Méndez Plancarte, México, I942, págs. xxxv-xxxvi y I39-I4I.

${ }^{6}$ Víctor Adib, reseña citada de Huíf (supra, nota I) y artículo de $A b s$, XIII, 1949, págs. 31 1-326: Fray Miguel de Guevara y el Soneto a Cristo crucificado. 
euentra aislado en el manuscrito del Arte: figura entre poesías análogas que, según los mencionados críticos, son obra de fray Miguel, el cual resulta así ser figura notable de la poesía espiritual del Siglo de Oro.

No creo fácil zanjar la cuestión de paternidad ciñendo el estudio a las poesías contenidas en el manuscrito mexicano. Hace falta tener en cuenta la corriente espiritual que desemboca en el soneto y la tradición literaria a que pertenece. Como estos dos aspectos del asunto han merecido hasta ahora poca atención, vale la pena dedicarles unas breves observaciones.

No se le ocultaba a M. Legendre el carácter nada vulgar, extremoso - no digamos extremista - de los sentimientos que se expresan en el soneto anónimo: "Son exactamente lo contrario de los atribuidos por la leyenda al tradicional catolicismo español: temor al infierno, o, a lo sumo, atracción de los goces del paraíso" ". No hay tal leyenda, según Sister Mary. La tradición de temor y esperanza es auténtico catolicismo, y católica también es la tradición del perfecto amor de Dios que halla expresión en el soneto. $\mathrm{Y}$ tan españolas son una como otra. Por eso procura la nueva doctora poner en evidencia el "traditional Spanish emphasis on Perfect Love of God"s. Lo hace reuniendo citas cuyo número podría crecer todavía mucho más, ya que el amor desinteresado de Dios es tema básico de toda espiritualidad verdaderamente cristiana.

Pero con esta manera de proceder queda borrada la peculiaridad del tema del Soneto. Se trata de un extremo de amor casi tan sorprendente para la mayoría de los cristianos como el de la simbólica mujer que apareció, camino de Damasco, al P. Yves, dominico, allá en los tiempos de las Cruzadas. En una mano llevaba un braserillo de lumbre para quemar el paraíso, y en la otra un jarro de agua para apagar el fuego del infierno, a fin de que los hombres sólo amasen y sirviesen a Dios por amor. Semejante amor, inconcebible para millones de fieles, es ideal común a místicos cristianos y sufíes musulmanes ${ }^{10}$. Ya el Amado de Raimundo Lulio - místico cuyos contactos con el sufismo difícilmente se pueden negar - se quejaba porque

₹ Citado por Hurf, op. cit., pág. 63 .

8 Ibid., págs. 63-1 I.

9 Es curioso que Sister Mary (pág. 54) sólo se refiera en una nota de su libro a esta aparición relatada por el cronista Joinville, pues es la expresión más gráfica del concepto del soneto. Con el nombre de Caritée la adoptó Camus, discípulo predilecto de San Francisco de Sales, como símbolo del puro amor (La Caritée ou le pourtraict de la vraie Charité, i64o. Cf. Henri Bremond, Histoire littéraire du sentiment religieux en France, vol. XI, Le procès des mystiques, Paris, I933, pág. 202, donde puede verse un facsímil de la estampa grabada por Abraham Bosse para la portada del libro de Camus.

10 Según Miguel Asín, citado (pág. 54, nota) por Huff, que se refiere a la discusión de las ideas de Asín por Probst, Hatzfeld y otros, especialmente a propósito de la posible influencia del sufismo sobre Lulio. Útimamente ha vuelto a afirmar esta influencia Américo Castro, España en su historia, Buenos Aires, 1948 , págs. 289 y sigs. 
de mil hombres, ciento nada más le temían y amaban, y, de los ciento, noventa le temían porque no les diese pena, y diez le amaban porque les diese gloria; y no había apenas quien le amase por su bondad y nobleza ${ }^{11}$.

La fama internacional del soneto, traducido a muchas lenguas, es prueba de que el tema tiene eco perdurable en las minorías espirituales de toda la cristiandad. Pero la vida que tuvo en la España del Siglo de Oro es lo que nos importa. No necesitaba el poeta desconocido beber su doctrina en fuentes lejanas, cuando la encontraba formulada con mucha fuerza en el cap. L del Audi filia del Maestro Juan de Ávila:

Aunque no hubiese infierno que amenazase, ni paraíso que convidase, ni mandamiento que constriñese, obraría el justo por sólo el amor de Dios lo que obra ${ }^{12}$.

Pero en el Soneto es rasgo notable el que el amor incondicional del hombre sea correspondencia al infinito amor divino manifestado en la Redención. Es amor al Crucificado. También este sentimiento halló en Juan de Ávila una de sus expresiones más conmovedoras:

Guando yo, mi buen Jesús, veo cómo de tu costado sale el hierro de la lanza, esa lanza es una saeta de amor que me traspasa, etc... .

No solamente la cruz, mas la misma figura que en ella tienes nos llama dulcemente a amor; la cabeza tienes reclinada para oírnos y darnos besos de paz, con la cual convidas a los culpados; los brazos tienes tendidos para abrazarnos; las manos agujeradas para darnos tus bienes; el costado abierto para recibirnos en tus entrañas; los pies enclavados para esperarnos y para nunca te poder apartar de nosotros. De manera que mirándote, Señor, en la cruz, todo cuanto vieren mis ojos, todo convida a amor: el madero, la figura y el misterio, las heridas de tu cuerpo; y sobre todo, el amor interior me da voces que te ame y nunca te olvide mi corazón ${ }^{13} \ldots$

La doctrina del puro amor unida con el sentimiento de la Pasión redentora es característica del siglo $\mathrm{xvI}^{14}$, tan empeñado en hacer sentir

11 Traducción del texto catalán del Llibre d'amic e amat citado por HufF, op. cit., pág. 74 .

12 Jun de Avila, Obras espirituales, t. I, Madrid, 1941, págs. 162-163. (HufF, pág. 75. El texto citado a continuación del $\mathrm{P}$. Nieremberg merece lugar aparte como paráfrasis evidente del soneto).

13 Obras, ed. cit., t. II, pág. 22 (del Tratado del amor de Dios para con los hombres).

${ }^{14}$ Lo cual no quiere decir que no se dé en otras épocas. A principios del siglo xIII o fines del xn la expresa el seudo-San Anselmo en su meditación X, sobre la Pasión de Cristo ( $M L$, vol. 158, págs. 761-762). Después de la consideración de las llagas del Crucificado, exclama: "Nihil quaero nisi teipsum, quamvis nulla merces repromitteretur: licet infernus et paradisus non essent, tamen propter dulcem bonitatem tuam, propter teipsum adhaerere vellem tibi". 
a los cristianos su relación con Cristo. Culmina en Italia, entre los spirituali influidos por Juan de Valdés, en lo que no sin razón se da en llamar la escuela del Beneficio de Cristo.

Por eso es de sentir que falte en la antología espiritual de Sister Mary un texto de importancia crucial para la historia del "Perfecto Amor de Dios" en el siglo xvi. Me refiero a las páginas del Alfabeto cristiano ${ }^{\text {I5 }}$ de Juan de Valdés en que el "aristocrático alumbrado" español avecindado en Nápoles explica a Giulia Gonzaga un concepto que la escandalizaba en un sermón de Fra Bernardino Ochino. Había dicho el fraile

que solamente acepta Dios aquellas buenas obras que nosotros hacemos puramente movidos por el amor de Dios, sin que a ello nos mueva ni temor de infierno, ni deseo o amor de gloria ${ }^{16} \ldots$

He aquí cómo Giulia confiesa sus vacilaciones, y cómo triunfa de ellas Juan de Valdés:

G.-Ahora, para decir la verdad y hablar con vos libremente, queriendo yo examinar bien mi ánimo, hallo que no me movería a obrar cosa ninguna, si no fuese por temor del infierno, y a veces por amor de la gloria, mas ninguna por puro amor de Dios. Porque yo sé de mí que si no hubiese infierno ni paraíso, me lo pasaría muy bien en este mundo, viviendo en esta vida moral y loable a los ojos del mundo como he vivido hasta aquí, sin cuidarme de buscar más adelante. Ahora, siendo esto así como yo en verdad lo conozco en mí, y siendo verdad lo que el predicador dice, yo hallo por mi cuenta que todo lo que yo haré de esta manera será perdido, pues que en efecto conozco que no me muevo a ello por amor de Dios sino por amor mío. No sé yo cómo me podréis acomodar esto.

15 Las citamos por la traducción castellana de Usoz (vol. XV de Reformistas antiguos españoles), Alfabeto cristiano by JUAN dE VALDÉs, a faithful reprint of the Italian of 1546 , with two modern translations in Spanish and in English, London, I86ı, págs. I65-169. Ya al principio del diálogo (pág. 24), Valdés explica a Giulia la contrariedad que siente en sí misma, "Ia cual toda nace del amor propio con que os amáis a vos misma: teméis el Infierno por interés vuestro, amáis el Paraíso por interés vuestro; teméis la confusión del mundo por vuestro interés, amáis la gloria y el honor del mundo por vuestro interés. De suerte que en todas Ias cosas que teméis o amáis, mirado bien, os encontraréis a vos misma". Salir de sí mismo para entrar en Dios, es salir de contrariedad y descontento para hallar paz y alegría. Es camino seguro del Paraíso. El puro amor de Dios como única manera de superar el amor propio, tema fundamental de Juan de Valdés, lo es también de los maestros franceses del puro amor (Bérulle y Binet, adaptadores del Breve compendio intorno alla perfezione cristiana de Isabel Bellinzaga y del jesuíta Aquiles Gagliardi; y sobre todo Camus, discípulo querido de San Francisco de Sales, autor de La défense du pur amour contre les attaques de l'amour-propre $(\mathrm{I} 640)$.

16 El sermón de Ochino aludido por Valdés parece ser la Prédica XXIV. Traducimos de la selección publicada por G. Paladrno, Opuscoli e lettere di Rifor. matori italiani del Cinquecento, t. I (Scrittori d'Italia, vol. LVIII), Bari, 1913, pág. I27. 
V.-Así pudiese yo echar de vuestro ánimo todo vuestro amor propio como sabré acomodar eso.

G.-A la prueba.

V.- Vos tenéis, Señora, un esclavo, comprado por vuestros dineros: y aunque es vicioso, malvado y mal inclinado, le queréis bien; y para que él no ponga en efecto sus maldades y vicios, le amenazáis continuamente con la galera y con otros fuertes castigos. Si este tal esclavo tiene ingenio, por no ir a galeras y por no ser castigado ( $y$ aun entendiendo que vos le hacéis aquellas amenazas para bien suyo), no solamente trabaja para refrenar sus vicios, sino que comienza a quereros bien. Conociendo vos esto, comenzáis a tratarlo bien. El, sintiendo y gustando el buen tratamiento y la afición que le tenéis, comienza también a serviros con diligencia, para que le honréis y le deis de buen grado lo que ha menester. Así lo hacéis, y cuanto más vos, en esto, le mostréis el amor que le tenéis, tanto más crece en él el amor y voluntad que tiene de serviros. De modo que ya no se abstiene de los vicios y maldades por temor de la galera, ni es diligente en vuestro servicio por el buen tratamiento que le hacéis, sino por la buena voluntad y afición que conoce que le tenéis: y aunque no hubiese galeras, y aunque no le pudieseis tratar bien, no dejaría de serviros, porque se halla obligado por lo pasado, y porque conoce en vos que merecéis ser servida y obedecida. Entonces, viendo vos la bondad del esclavo, dándole carta de libertad, le hacéis libre, y ya él os obedece por amor y no por temor, y os sirve como libre, y no como esclavo, y por gratitud y no por interés. De este mismo modo se porta Dios con nosotros, porque conoce la mala inclinación, la malignidad y la iniquidad de que somos herederos por el pecado de nuestros primeros padres, queriéndonos bien por habernos criado y redimido con la preciosísima sangre de su Hijo Jesu Cristo, nuestro Señor: y para que no pongamos en ejecución nuestros desordenados apetitos, nos pone delante el infierno. Y de aquí nacen las continuas amenazas de que está llena la sagrada Escritura. Los que, de nosotros, abrimos los ojos y creemos que hay infierno y sabemos de cierto que Dios hará lo que dice en castigar nuestros vicios con las penas del infierno, trabajamos por apartarnos de los vicios, para no incurrir en la pena, y asimismo porque en algún modo conocemos que Dios nos ama. $\mathrm{Y}$ en tal caso, aun cuando no nos movamos por puro amor, todavía Dios, vista nuestra obediencia, nos abre más los ojos a fin de que conozcamos el bien del Paraíso. Conocémosle, y deseándole comenzamos a aplicarnos a hacer la voluntad de Dios para que nos dé su gloria. Entonces, aceptando Dios nuestra buena voluntad, nos abre más los ojos para que conozcamos de una parte nuestra malicia y de otra su infinita bondad. Con este conocimiento comenzamos a enamorarnos de Dios y a obedecerlo y servirlo, no ya por miedo del infierno ni por amor de la gloria, sino solamente porque hemos conocido que El es digno de ser amado y que infinitamente nos ama. Entonces Dios nos da carta de libertad, y nosotros no salimos de su servicio por haber tenido la libertad, antes le esta- 
mos más sujetos y más obedientes, pero no como esclavos, sino como libres, no como mercenarios, sino como hijos: y en esto consiste la libertad cristiana...

Ochino, capuchino que se pasó a Ginebra, Juan de Valdés, evangelista de la aristocracia napolitana, y también Juan de Åvila, apóstol de Andalucía, son tres exponentes de la espiritualidad dominada por el Beneficio de Jesucristo. Espiritualidad de vanguardia que fué la gran víctima del Indice español de 1559 porque su insistencia en la salvación por los méritos de Jesucristo olía entonces a cosa de "luteranos o alumbrados". Pero Juan de Åvila y su más fecundo discípulo Luis de Granada - dos de los autores prohibidos de 1559- sortearon las dificultades. Refundidas sus obras sin merma notable de la inspiración primitiva, alcanzaron una resonancia inmensa. Algo esencial de la espiritualidad del Beneficio (que también sobrevive en hermosas páginas de Fr. Diego de Estella) se transmitió así a un extenso público, tanto monástico como seglar, a fines del siglo xvI y principios del xvII.

Nada más probable, pues, que la filiación aviliana del soneto $A$ Cristo crucificado $^{17}$. ¿Circularía anónima esta poesía por miedo a la acusación de iluminismo? No es del todo absurdo pensarlo, aun cuando el sentimiento del soneto sea intachablemente ortodoxo. Desde luego, sería arbitrario relacionarlo con la opinión de los alumbrados del reino de Toledo, que negaban el infierno y lo consideraban inventado para espantar a los hombres como el coco a los niños ${ }^{18}$. Pero la exigencia del puro amor era común a místicos y alumbrados; y otra de las proposiciones censuradas en el edicto de 1525 contra los alumbrados es que "las buenas obras que hacen los hombres por amor de Dios no las hacen por amor de Dios sino por sus propios intereses" "19. Dice Menéndez y Pelayo (no se sabe con qué fundamento) que el pensamiento de nuestro soneto, "mal entendido por los quietistas, les sirvió de texto para su teoría del amor puro y desinteresado" 20. El tal amor bien podía parecer sospechoso a los que

17 Helmut A. HatzFeld (The infuence of Ramon Lull and Jan van Ruysbroeck on the language of the Spanish mystics, en Trad, IV, 1946, pág. 344) insiste en la forma condicional de los tercetos ("the concessive-conditional form which makes the sonnet theologically so acceptable and stylistically so reminiscent of a concepto espiritual of the baroque type..."). Pero no se fija en el texto del Audi flia que tiene exactamente la misma forma (cf. también el texto del seudo-San Anselmo citado supra, nota 14). Creo que el aspecto estilístico es de poca monta frente a la exigencia del pensamiento, de la cual es mero reflejo. Se trata de un extremo de amor, llevado hasta la hipótesis irreal (el "imposible") de que no haya paraíso, infierno ni ley. Nótese que el progreso espiritual descrito por Juan de Valdés implica también la realidad del infierno y del paraíso, aunque en la etapa final no interviene ya ni miedo del infierno ni amor de la gloria.

18 Edicto de los alumbrados de Toledo (Arch. Hist. Nac. de Madrid, Inquisición, lib. 1 299, fol. $55^{2} \mathrm{r}^{\circ}$ ), Prop. $\mathrm{n}^{2} \mathrm{I}$.

19 Ibid, Prop. XXXVII (cf. $\mathrm{n}^{\circ} 18$ de la Memoria que contiene los delictos de los alumbrados, ibid., fol. $\left.549 \mathrm{v}^{\circ}\right)$.

20 Loe. cit. En vano buscaron confirmación de esta idea Carreño y Sister Mary 
tenazmente denunciaban como dañinos para la ortodoxia no sólo el misticismo de Santa Teresa y San Juan de la Cruz, sino también la espiritualidad de Juan de Ávila y Luis de Granada ${ }^{21}$. A todo lo que fuera misticismo o cosa parecida se imponía la prudencia.

Sin embargo, el velo que cubre la personalidad del autor puede explicarse de otro modo. El soneto anónimo es problema para nosotros no tanto por expresar un concepto excepcional como por ser expresión poéticamente bella del mismo. Pertenece a una amplia tradición de sonetos espirituales en la cual hay maravillas firmadas por Góngora, Bartolomé de Argensola y sobre todo Lope de Vega, y no faltan tampoco colecciones firmadas por frailes, como el "Garcilaso a lo divino" de Fr. Sebastián de Córdoba, que ejerció su influencia, a pocos años de publicarse, sobre la creación poética de San Juan de la Cruz ${ }^{22}$. Dominan artísticamente el género los cien sonetos de las Rimas sacras ( I6I $_{4}$ ) de Lope de Vega. A varios críticos les llamó la atención cierta analogía entre el soneto $A$ Cristo crucificado y algunos de los lopescos ${ }^{23}$. Analogía formal, de técnica y de resonancia más bien que de contenido. Porque, si es cierto que reina en ambas partes el amor al Crucificado, no asoma en Lope el tema del perfecto amor indiferente a las remuneraciones de ultratumba.

Manuel de Montoliứ ${ }^{24}$ es quien más ingeniosamente procuró unir el

C. Huff (pág. 58, nota) en la obra de H. BREmond, Histoire littéraire du sentiment religieux en France. La obra quedó interrumpida por la muerte del autor antes de llegar al famoso debate del quietismo (aunque Bremond trató de él en su Apologie pour Fénelon). Sin embargo, en el ya citado vol. XI (Le procès des mystiques), los ataques del P. Antoine Sismond contra Camus están estudiados como prefiguración del mismo debate ("préquerelle du quiétisme"). Allí se ve cómo Camus había enseñado a unas monjas, en la Derecha intención de Drexelius, el grabado simbólico de Caritea, o sea del perfecto amor, apagando el infierno y quemando el paraíso, por cuyo modelo se pintó un cuadro para la comunidad. No fué necesario más para que los enemigos de la espiritualidad acusaran a Camus de sacrilegio e impiedad "comme abolissant tous les fondements de la religion, anéantissant l'enfer et le paradis dans la foi et le souvenir des chrétiens" (BREmond, op. cit., vol. XI, pág. 202). Es evidente que no era ésa la intención del obispo de Belley, discípulo de San Francisco de Sales. Pero se ve que el pensamiento del soneto, en su forma más gráfica, sirvió a los "prequietistas" franceses de la época de Luis XIII para expresar su doctrina del Puro Amor.

2I Cif. los estudios recientes del P. V. Beltrán de Heredia en RET, VII, 1947 , págs. 373-397 y 483-534: Un grupo de visionarios y pseudoprofetas que actúa durante los últimos años de Felipe II: Repercusión de ello sobre la memoria de Santa Teresa, y IX, 1949, págs. 161-222 y 445-488: Los alumbrados de la diócesis de Jaén.

22 Cf. Dámaso Alonso, La poesía de San Juan de la Cruz, Madrid, 1942, págs. 47 y sigs.

${ }_{23}$ Montoliú (cf. nota 24) y J. Hurtado y A. González Palencia, Historia de la literatura española.

24 En su selección del B. JuAn DE Ávila, Epistolario (en la Biblioteca Clásica Ebro, vol. 17, Zaragoza), págs. 27-28. 
soneto anónimo a la colección de Lope mediante una ecuación literaria. Fijándose en la elaboración del hermosísimo soneto XIV de las Rimas sacras, "Pastor, que con tus silbos amorosos...", notó que el terceto final

Espera pues, y escucha mis cuidados ...

Pero ¿cómo te digo que me esperes, si estás, para esperar, los pies clavados?

se inspiraba en un trozo de Juan de Ávila ${ }^{25}$. Para este remate sacado de sus lecturas espirituales forjó el poeta penitente los once versos anteriores con todas sus bellezas, en particular la estupenda imagen del buen Pastor con las manos en alto, colgadas del cayado, o sea el palo horizontal de la Cruz.

Analizado en igual forma el soneto No me mueve, mi Dios..., resulta que sus tercetos coinciden con otro párrafo de Juan de Ávila, y los cuartetos no hacen más que desarrollar sobriamente el contraste entre los impuros motivos de esperanza y temor, y el amor desinteresado a Cristo crucificado. "La seguridad de haberse Lope inspirado en el Maestro Ávila en el primer caso hace más probable su paternidad respecto del segundo".

No convence el razonamiento. El estilo es otro. No hay en todas las Rimas sacras un solo soneto tan desprovisto como No me mueve... de esos hallazgos expresivos que derrocha la pluma de Lope, no hay otro tan fundado en mero vigor afirmativo e insistente. ¿Bastarán analogías generales de fuentes y estructura para probar la unidad de autor? ¿Será preciso suponer que Lope escribió el soneto famoso y no le dió lugar entre los suyos por juzgarlo inferior? ¿ $\mathrm{O}$ por considerarlo atrevido? La realidad es probablemente más sencilla y más compleja.

Baste decir que Lope de Vega no inventa la técnica del soneto espiritual. La encuentra ya muy formada en el momento de su conversión. Tiene modelos nada difíciles de puntualizar. Unas veces sigue la vía trillada de volver Garcilaso a lo divino ${ }^{26}$. Otras se acuerda de unos hermosos poemas incluidos por Fr. Pedro Malón de Chaide en La conversión de la Magdalena ( (592). Aquí encontramos un soneto del Hijo pródi$\mathrm{go}^{27}$ que arranca, como el XIV de las Rimas sacras ("Pastor que con tus silbos..."), de una parábola evangélica, para acabar en evocación del Crucificado que espera al penitente:

${ }^{25}$ Texto citado supra, pág. 256. El texto de Fr. Diego de Estella (Meditaciones devotísimas del amor de Dios, med. XVIII) citado por M. Batalllon, Erasmo y España, México, 1950, vol. II, pág. 376, deriva evidentemente del tratado aviliano del Amor de Dios, ya muy difundido antes de 1558 en copias manuscritas.

${ }^{26}$ EI soneto I de las Rimas sacras es imitación del soneto I de Garcilaso, ya vuelto a lo divino por Sebastián de Córdoba (cf. Romancero y cancionero sagrados, en Bibl. Aut. Esp., vol. XXXV, pág. 5 I b).

${ }_{27}$ Bibl. Aut. Esp., vol. XXVII, pág. 334 a: De padre y de consejo despedido... 
¿Si huye? No hará, que en un madero me espera el buen Jesús, por mí enclavado y el corazón rasgado, a do esconderme.

$\mathrm{Y}$ es de notar que en el mismo libro de Malón de Chaide ${ }^{28}$, en una paráfrasis en tercetos del cap. viI de $J o b$, aparece el buen Pastor con su amoroso silbo:

Sólo invoco, oh mi Dios, ese tu oficio; y pues eres pastor, busca tu oveja que se descarrió por solo vicio.

Llegue, Pastor, tu silbo hasta su oreja. Vuélvela, guarda fiel, a tu manada, haz que deje la mala yerba vieja.

El soneto XV de las Rimas sacras ("¿Cuántas veces, Señor, me habéis llamado... ?"”) lleva también alguna reminiscencia de otro incluido en La conversión de la Magdalena ${ }^{29}$ y muy difundido a fines del siglo xvI:

¡Oh paciencia infinita en esperarme!

¡Oh duro corazón en no quereros!

¡Que esté yo ya cansado de ofenderos

y que no lo estéis vos de perdonarme!

Cuántas veces volvistes a mirarme esos divinos ojos, y a doleros, al tiempo que os rompía vuestros fueros, ¡y vos, mi Dios, callar, sufrir y amarme!

Es, pues, evidente que en las Rimas sacras de Lope se hace más consciente, más ágil y creadora una técnica del soneto espiritual cultivada antes y después por frailes $u$ otras personas devotas que no eran poetas de profesión y no acostumbraban firmar sus poesías.

Nos interesa recalcar que el soneto $\mathrm{O} h$ paciencia infinita $\ldots$ ! y el del Hijo pródigo van incluidos en la obra de Malón de Chaide como poesías anónimas y que sólo por inadvertencia han podido atribuirse a Fr. Pedro. El autor, en estos dos casos y en otro más, dice bien claro que los versos que cita no son suyos ${ }^{30}$. Y no se crea que lo hace por ascético desprendimiento, pues el mismo Malón de Chaide intercala varias paráfrasis de Salmos sin insinuar que son de otro, y no tiene reparo en confesarse autor de la adaptación del soneto de Gabriel Fiamma que ofrece junto con el original ${ }^{31}$.

28 Ibid., pág. $34^{1}$ a.

29 Ibid., pág. 318 b.

30 Ibid., pág. 334 a: "como nos lo dijo bien uno en los versos siguientes"; pág. 318: "... el que hizo este soneto... y por parecerme que lo concluyó bien he querido ponello aquí", cf. pág. 291 b: "y porque vi este capítulo $4^{\circ}$ del profeta Amós traducido a la letra, he querido ponerlo aquí..."

31 Ibid., pág. 382 b. 
¡Oh paciencia infinita...! figura - también rigurosamente anónimo- en dos manuscritos de miscelánea poético-religiosa de la biblioteca del Escorial: no sin motivo compara el P. Villalba ${ }^{32}$ el caso de este son eto con el de No me mueve, mi Dios... Otro caso semejante es el del Soneto del gran bien que es servir y amar a Dios (Inc.: "iQué libertad está en obedecerte...!" Expl.: "la eternidad promete de tu gloria") que figura en dos manuscritos escurialenses ${ }^{33}$ a vueltas de diversas poesías de Arias Montano y Fr. José de Sigüenza. El P. Villalba nota que en esta colección "no se hizo gran cuenta de señalar el nombre del autor de cada pieza poética" 34; y opina que el soneto iQué libertad está en obedecerte...! no debe de ser obra de Sigüenza. En otros términos, debe de ser un anónimo más.

Con estas advertencias quedamos preparados para interpretar correctamente la presencia del soneto No me mueve, mi Dios ... en las colecciones poéticas donde aparece por primera vez.

Viene impreso en 1628 en la obra del Dr. D. Antonio de Rojas, Presbítero, titulada Vida del espíritu para saber tener oración y unión con $\operatorname{Dios}^{35}$. A nadie se le puede ocurrir que las poesías puestas al principio del libro sean obra de Rojas, aunque no llevan nombre de autor. Entre los preliminares figuran la célebre poesía Al interior ("Entréme donde no supe ..."), umiversalmente tenida por de San Juan de la Cruz, y unos aforismos del mismo Doctor (Modo para venir al todo; Modo de tener al todo), copiados, con poquísimas variantes, de la Subida al Monte Carmelo. Al final del tomo hay una colección más nutrida de sonetos, glosas y canciones que lleva el título corriente de Poesía mística, y es donde aparece nuestro soneto ${ }^{36}$.

Así como un romance heptasilábico Al santísimo Sacramento va precedido de un tratado breve de la Comunión frecuente, el Soneto A Cristo Crucificado viene a continuación de un ejercicio de aniquilamiento de la voluntad propia. Vale la pena copiarlo por la relación que guarda con el soneto.

32 Fr. José de Sigüenza, Historia del Rey de los reyes..., con un estudio preliminar sobre el P. Sigüenza y sus obras por el P. Luis Villalba Muñoz, vol. I, EI Escorial, 1916, pág. ccxxn.

33 Ibid., págs. cxcv (núm. 48) y ccxxvi (núm. 396).

34 Ibid., pág. clxxxvir.

35 Sólo hemos tenido a mano la reimpresión de Madrid, r63o (Viuda de Alonso Martín). Suponemos que la colocación de las poesías es igual a la de la primera edición.

36 EI P. Cyprien de la Nativité, muy conocido como traductor de San Juan de la Cruz, tradujo al francés La vie de tesprit de Antonio de Rojas. Allí figura (pág. $23^{1}$ de la edición de París, r646) su versión de Á l'intérieur ("J'entray sans sçauoir ou c'estoit..."). Pero no tradujo el soneto No me mueve, mi Dios..., del cual no se conoce ninguna traducción francesa anterior al siglo xviI. Parece increíble que pasara inadvertida esta poesía en Ia Francia del siglo xvir y que no intentara nadie traducirla. 


$\begin{array}{ll}\text { Preg. ¿Quieres gusto? } & \text { Resp. No } \\ \text { ¿Quieres honra? } & \text { No } \\ \text { ¿Quieres libertad? } & \text { No } \\ \text { ¿Quieres ciencia? } & \text { No } \\ \text { ¿Quieres ignorancia? } & \text { No } \\ \text { ¿Quieres gozos? } & \text { No } \\ \text { ¿Quieres seguridad? } & \text { No } \\ \text { ¿Quieres gloria? } & \text { No } \\ \text { ¿Quieres infierno? } & \text { No }\end{array}$

Pues ¿qué quieres? Sólo la honra y gloria de Dios y que todos enteramente hagamos su voluntad Porque esto es quererle sin interés, y diciendo que no quieres, esto es querer todo lo que él quisiere dar.

Entre día podrás usar destas sentencias breves por la calle, que será como traer un poco de alcorza en la boca: y sírvate sólo para recogerte, no parándote ai. Y para lo mismo te sirve toda la poesía [es decir, la poesía mística aquí coleccionada. El subrayado es nuestro].

¡O quién lo perdiese todo por buscar a Dios sin modo!

¡O quién me hiciese olvidar cuanto yo puedo pensar!

¡Quién me diese navegar y engolfado no remar!

¡O quién lo dejase todo por ir al todo en todo!

¡Quién dejase de querer esto que parece ser!... etc.

$\mathrm{Y}$ terminadas estas piadosas aleluyas se lee el aviso siguiente:

La inteligencia de todo esto hallarás en este breve tratadillo. $\mathrm{Y}$ así, si ignorares algo de lo que aquí leyeres, no te aflijas sino resígnate y asiéntate en el polvo de tu humildad, no queriendo entender más de lo que Dios quiere que entiendas. No has de tomar pena de nada, sino de haber ofendido a Dios y de que haya quien le ofenda: y de que tú y todos no hagan enteramente su voluntad.

Aquí entra nuestro soneto... Pudiera surgir la scspecha de si Rojas es autor de los versos como lo es de la prosa con que los acompaña. Pero se ve que no hay adecuación perfecta entre el tema del soneto y la doctrina de aspiración al Todo por la Nada que lo antecede, sirviendo de engarce el consejo "no has de tomar pena de nada, sino de haber ofen- 
dido a Dios", etc. ... Más que valor doctrinal tiene "toda la poesía", según dice Rojas, valor instrumental. Sirve para meditar brevemente y recogerse sin pararse en ella. $\mathrm{Y}$ es de notar el descuido con que se imprime nuestro soneto, pues parece errata

en vez de

$$
\text { para dejar por eso de quererte }
$$

$$
\text { para dejar por eso de ofenderte } e^{37} \text {. }
$$

Lo razonable es pensar que el Dr. Antonio de Rojas, en i628, echó mano de esta y otras poesías como de bienes mostrencos, porque las juzgaba a propósito para hacer brotar la chispa del amor divino.

Por los mismos años encarga el papa Urbano VIII la revisión de los himnos del Breviario romano a los jesuítas Strada, Gallucci, Sarbiewski y Petrucci ${ }^{38}$. En el nuevo himnario de ${ }^{6} 6_{3}$ I parece que se imprime por primera vez el himno atribuido a San Francisco Javier ${ }^{39}$

$$
\begin{aligned}
& \text { O Deus ego amo te, } \\
& \text { nec amo te ut salves me... }
\end{aligned}
$$

que coincide con el soneto en sus conceptos y movimiento sin ser exactamente igual. Bien pudo ser adaptación de la poesía española por algún jesuíta $^{40}$. Pero hay que rechazar la idea de que esta adaptación se hizo

37 G. Schurhammer y J. Wicki, op. cit., págs. 527-529, dan un aparato crítico y clasificado del soneto más completo que el de Sister Mary C. Huff.

38 Pierre Batiffol, Histoirc du Bréviaire romain, Paris, I893, pág. 262.

39 Según el artículo Hymns de Lord Selborne en la Encyclopadia Britannica, vol. XII (algo ampliado en edición aparte. Cf. Roundell, Earl of Selborne, Hymns, their history and development, London, 1892, pág. 73) citado por HuFf, págs. i 2 y 39 . Es de extrañar que los PP. Schurhammer y Wicki, op. cit., págs. $53^{0-53} \mathrm{I}$, en su eruditísimo estudio sobre el origen del soneto, no aludan a esta afirmación de Selborne, ni siquiera para refutarla, y den el himno $O$ Deus ego amo te como publicado por primera vez en la Medulla sacrarum precationum impresa en Viena de Austria en I66ı. Ni a Sister Mary ni a mí nos ha sido asequible el Breviario de $\mathbf{6} 63$. Sería interesante ver como se presenta en él lo que Lord Selborne llama "a then recent hym of St. Francis Xavier". ¿Pasaría por obra poética del santo? ¿O meramente por expresión a decuada de su amor de Dios ("affectus amoris S. Francisci Xaverii"), compuesta en honor suyo, así como el propio Urbano VIII compuso en honor de Santa Martina y Santa Isabel de Portugal sendos himnos que entraron en el Breviario de i63 I? (Cf. BatifFol, loc. cit.).

40 Es plausible la hipótesis de Sister Mary C. Huff (pág. 39, nota) de que el himno $O$ Deus ego amo te naciera con ocasión de la canonización de San Francisco Javier en I622. Pero es francamente inverosímil que le sirviera de base el soneto "en una versión portuguesa o tal vez española copiada en la India, de puño y letra de San Francisco Javier”. El himno pudo tomar pie en el soneto anónimo e inspirarse en una copia que anduviese en Goa, antes de 1620 , incluida en una colección de papeles javerianos, si bien Schurhammer y Wicki (op. cit., pág. 530) afirman que el soneto fué llevado a la India en I660 por el P. Filippucci, y no traído de 
tomando como base el soneto copiado por el propio Francisco Javier, ya que el santo se embarcó para la India antes de publicarse la primera edición de las obras de Boscán y Garcilaso, y murió ( I 552) antes de que cundiera la moda del soneto espiritual, que apenas apunta en el primer Cancionero de Jorge de Montemayor (Amberes, I 554) ${ }^{4 \mathrm{I}}$. También pudo ser, por otra parte, que el himno latino, compuesto algunos años antes, sirviese de modelo al soneto que recogió Rojas. Desde luego, si llega a confirmarse, la publicación del himno en el Breviario romano de I6 3 , a tan pocos años de distancia de la publicación del soneto por Rojas, es hecho de gran trascendencia para la historia del soneto.

Sentado esto, ¿qué significación tendrá la presencia de media docena de poesías espirituales - una de ellas nuestro soneto-- en el manuscrito del Arte doctrinal . . para aprender la lengua matlaltzinga ( $634^{-1} 63^{8}$ ) por Fr. Miguel de Guevara? ¿Habrá que pensar, como lo admiten los partidarios del origen mexicano, que el soneto $A$ Cristo crucificado fué compuesto en la Nueva España bastantes años antes de ser copiado por el autor con su Arte doctrinal, y viajó de América a España antes de I628, a Roma antes de i63i?

No parece que conquistara fama de buen poeta el benemérito misionero de Michoacán. Al frente de su obra manuscrita inserta dos poe-

allá por él, como falsamente pretendió Possino. No es absurdo pensar que el soneto se escribiera entre 1622 y I628 a imitación del himno "javeriano", si éste se remonta a 1622. La idea del himno pudo brotar de las seis oraciones en honor de la Pasión forjadas por Mendes Pinto en su Peregrinaçam (Lisboa, 1614), obra que antes de imprimirse fué utilizada por los primeros biógrafos del santo, Tursellini y João de Lucena (Schurhammer-Wigki, op. cit., pág. 526). La hipótesis de que el soneto tenga un prototipo en un himno latino compuesto en 1622 por un jesuíta italiano no excluye la posible filiación aviliana de su tema, pues es bien conocido el interés de la Compañía por la persona y obra del Maestro Avila, y andaban en lengua italiana sus escritos: desde 1580 el Audi flia, desde 1620 el Tratado del amor de Dios para con los hombres (Cf. LuIs SALA BALUst, Ediciones y manuscritos italianos de las obras del P. Maestro Avila, en $M A$, II, 1948, págs. 133 y 139). Y además, el español autor del soneto pudo acordarse del texto de Avila, siguiera o no la pauta dei himno latino en la composición de su poesía.

41 Tal vez se den hacia $155^{\circ}$ algunos casos aislados. Merece notarse que el Licenciado Buenaventura de Morales pone dos sonetos en loor de Cristo crucificado, fuente de toda vida y de toda paz, al final del prólogo Al lector de su traducción de las Obras espirituales de Serafino da Fermo (Amberes, 1556; no he comprobado si existen los sonetos en la edición de Burgos, 1553, y en la de Salamanca, 1552, que ha de ser la edición príncipe). El que el Licenciado Buenaventura de Morales sea el traductor de un famoso místico italiano hace pensar en posibles modelos de sonetos espirituales venidos de Italia. Sobre los orígenes italianos del género da una valiosa indicación J. G. Fucilla (The pedigree of a "soneto a lo divino", en CompL, I, I949, pág. 267) al referirse al Petrarca spirituale (Venezia, 1536) de Gerolamo Mahpiero, típico precedente del "Garcilaso a lo divino" de Fr. Sebastián de Córdoba. También cita, entre los seguidores de Malipiero, a Feliciano Umbruno da Civitella (Dialogo del dolce morire di Gesù Cristo sopra le sei visioni di M. Francesco Petrarca, 1544) y a Gian Giacomo Salvatorino (Thesoro de Sacra Scrittura sopra Rime del Petrarca, I547). 
sías en elogio de la misma, debidas al secretario del provincial de los agustinos de la Nueva España, Fr. Bernardo de Alarcón. Alaba fray Bernardo a su hermano de buen lingüista y predicador, sin aludir para nada a su talento poético. Que fray Miguel era capaz de versificar -y con mediana gracia - lo dan a entender dos poesías (redondillas y soneto) dirigidas por el autor a su Arte. Las demás poesías repartidas entre el principio y el fin del manuscrito no se dan por obras de Guevara. Su colocación $^{42}$, con la circunstancia de repetirse al fin dos de las composiciones incluidas al principio (el soneto No me mueve y la octava real $E l$ tiempo vuela...), hace suponer que el misionero aprovechó unas páginas en blanco para copiar poesías de su predilección más bien que para recopilar poesías propias ${ }^{43}$.

Es verdad que, además de No me mueve, mi Dios..., se encuentran aquí dos sonetos espirituales nada despreciables, y no descubiertos hasta la fecha en otras colecciones. Decir que informa a los tres el mismo amor a Cristo crucificado y el mismo remordimiento de ofenderle no es prueba suficiente de que salieran los tres de la misma pluma y de la del agustino Guevara. Pues la inspiración es común a una amplia corriente de espiritualidad y a una escuela de sonetistas cristianos que florece durante bastantes decenios después de mediados del siglo xvi.

Si nos fijamos en el soneto Levántame, Señor, que estoy caído... rastreamos en él reminiscencias de los versos devotos de Jorge de Montemayor, adaptador de Savonarola ${ }^{44}$, y sobre todo de la epístola de San

42 Descrita de manera exacta por Víctor Adis, art. cit. de Abs. Insiste Adib en el hecho de que Fr. Miguel de Guevara copia en su manuscrito el tratado de Gregorio López sobre el Apocalipsis, y lo pone con el nombre de su autor, mientras que da $\sin$ nombre de autor las poesías que copia. La diferencia se explica muy bien si estas poesías llegaron anónimas a las manos de fray Miguel.

43 Una duda importante que no veo planteada ni por V. Adib ni por Carreño (en sus Consideraciones nuevas) es la de si el manuscrito es autógrafo de fray Miguel. Por los facsímiles que publica A. M. Carreño (uno de ellos, pág. 55, la última página, firmada por el autor, del prólogo del Arte doctrinal) se inclina uno a creer que sí. En tal caso, y en la hipótesis de copiar el autor poesías propias, sorprenden las imperfecciones en el texto de los sonetos. Entre las dos copias del soneto No me mueve... hay variantes más serias que las de mera grafía ("clauado en una crus y escarnesido" - "clauado en una crus escarnecido"; "muebe en fin tu amor" - "Mueueme en fin tu amor"). En el soneto Levántame, Señor..., ha tenido que suplir dos palabras A. Méndez Planearte en su citada edición (Poetas novohispanos, pág. 140): "a un tiempo muero y vivo, triste y ledo" (también pudiera uno pensar en otro ritmo: "a un tiempo muero triste $y$ vivo ledo", con una reminiscencia del "Vive leda si podrás" recordado por Juan de Valdés). Y sospecho que hay que corregir el verso siguiente: "lo que puedo hacer, eso no puedo", sustituyendo el primer puedo por quiero (cf. infra, nota 45).

44 El Cancionero del poeta Jorge de Montemayor (Sociedad de Bibliófilos Españoles, Madrid, 1932), pág. 304: "Mi ánima caída se levante..."; pág. 306: "Levántame en su sangre, que me cayo"; pág. 308: "Levántame otra vez, que estoy caído". (Sobre la procedencia savonaroliana de este poema, cf. Batall source de Gil Vicente et de Montemor: La Méditation de Savonarole sur le Mi- 
Pablo a los Romanos ${ }^{45}$. En cuanto al que empieza "Poner al Hijo en cruz abierto el seno", se le nota (con una analogía gongorina ya señalada por A. Méndez Plancarte ${ }^{46}$ ) la huella del mismo tratado de Juan de Ávila que directa o indirectamente inspiró a Lope el soneto Pastor que con tus silbos; y el último terceto expresa con vigor el tema fundamental de la deuda por el Beneficio de Cristo.

Estas poesías nos remiten, más bien que a una personalidad de escritor, a una corriente viva de la espiritualidad católica. Poesía inspirada y utilitaria a un tiempo, puede decirse que versos de esta índole fueron el mejor vehículo del sentimiento religioso que alentaba en ellos. No es de extrañar que muchas poesías de éstas, y no de las peores, circularan anónimas. Ni a los autores les interesó firmarlas ni les importaba el nombre del autor a los que las copiaban y recitaban.

serere, en $B E P I, \mathrm{III}$, I936, págs. I-I6). Véase también, pág. 304, el soneto: "Si un corazón caído se levanta..."

45 Rom., VII, I5-2I. Especialmente I9: "Porque no hago el bien que quiero; mas el mal que no quiero, éste hago". Dice el soneto debidamente corregido (cf. supra, nota 43 ):

Estoy, siendo uno solo, dividido:

a un tiempo muero triste y vivo ledo;

lo que quiero hacer, eso no puedo;

huyo del mal y estoy en él metido.

46 Poetas novohispanos, vol. cit., pág. I4 I. El soneto de Góngora a que se refiere Méndez Plancarte empieza: "Pender de un leño traspasado el pecho..." Juan de Ávila, en el Tratado del amor de Dios para con los hombres, ensalza la mayor prueba de amor de Dios con las palabras de San Juan en su evangelio (III, I6) y en su primera epístola (I Juan, IV, 9): "En esto conocemos el amor que Dios nos tiene, que nos dió a su hijo para que vivamos por él" (Obras, ed. cit., vol. II, pág. I I). A continuación expone cómo a la Humanidad de Cristo se le dió el Ser Divino. El soneto aprovecha con alguna ingenuidad esta idea del ser de Dios dado al hombre, llegando a imaginar una inversión de papeles, en que el hombre (Dios por hipótesis) diera a Dios (por hipótesis hombre terreno) el ser divino, y se quedara con la humanidad "a trueque de gozar un Dios tan bueno". Tiene razón V. Adib cuando nota una analogía temática entre este soneto y la conceptuosa décima contenida en el mismo manuscrito ("Murió Dios...)

$$
\begin{aligned}
& \text {... es muy cierto que murió } \\
& \text { por vida del hombre muerto... } \\
& \ldots \text {.. quién cien mil vidas tuviera } \\
& \text { con que en amor os pudiera } \\
& \text { pagar censo de por vida. }
\end{aligned}
$$

Acaba el soneto:

Deudor quedará siempre por derecho de la deuda que en cruz por mí ha pagado el Hijo por dejaros satisfecho.

Tal tema no es propiedad de nadie. Del manojo de poesías copiadas por fray Miguel con su Arte de lengua matlaltzinga sólo se puede inferir que el misionero cultivaba una espiritualidad - probablemente aviliana - fundada en la consideración del Beneficio de Cristo. 
El interés del hallazgo de Alberto $M^{a}$ Carreño estriba, pues, no en resolver el problema del autor de No me mueve, mi Dios . . ., sino en proporcionarnos un dato capital para la historia de su difusión. Además, enriquece el tesoro de la poesía espiritual anónima con otros dos sonetos ${ }^{47}$ de positivo mérito, que no sabemos si pasaron de España a México o si se escribieron en algún convento de la Nueva España, mereciendo por esta circunstancia figurar en el florilegio de Poetas novohispanos en que los incluyó A. Méndez Planearte bajo el nombre de Fr. Miguel de Guevara.

Quédese el famoso soneto en su anónimo ${ }^{48}$, con tal que entendamos bien lo que significa. Es un momento de la espiritualidad "cristocéntrica", un eslabón aviliano de la cadena que une la escuela italiana de los spirituali y del Beneficio de Cristo con la escuela del Puro amor que florece en la Francia de Luis XIII. Es anónimo adrede, pero sin segunda intención. Y si tanto fascina el misterio de quiénes fuesen los autores de la Celestina y del Lazarillo, artistas muy conscientes de su aportación a la literatura, y quisiéramos adivinar por qué recataron su personalidad, importa mucho menos poner nombre de autor a un soneto compuesto sin más ambición literaria que la de dar fuerza comunicativa a un extremo de amor de Dios.

Collège de France.

Marcel Bataillon

47 No pertenece a la misma clase de poesía el otro soneto desconocido del manuscrito ("Pídeme de mí mismo el tiempo cuenta..."). "Magistral, según A. Méndez Planearte, en su amanerado género conceptista", se sujeta al pie forzado de repetir las palabras tiempo y cuenta en cada verso, acabando siempre por una de ellas; y estira mucho una materia que da poco de sí.

${ }^{48}$ A la misma conclusión llegan los PP. Schurhammer y Wicki, op. cit., pág. 535, que niegan toda relación de San Francisco Javier con el soneto expañol o con cualquier versión latina del mismo. Creemos necesario matizar esta negación admitiendo que el himno $O$ Deus ego amo te (que no es propiamente una versión del soneto) pudo nacer como homenaje póstumo al santo en la época de su canonización. 